\title{
ESTUDIOS
}

\section{Definición de un modelo evolutivo para las entidades de financiación inclusiva}

\section{Àngel Font i Vidal ' y Carlos Moslares García'}

Palabras clave: Exclusión financiera, cajas de ahorros, microcrédito.

Key words: Financial Exclusión, Savings Banks, Microcredit

\section{Introducción}

La práctica del microcrédito está muy próxima al código genético de las cajas de ahorros.

Gabriel Ferraté (2000)

Esta frase apareció en un artículo firmado por el Profesor Gabriel Ferraté, fundador y primer rector de la Universitat Oberta de Catalunya y Presidente de Caixa Tarragona. Desde el primer momento su mensaje cautivó a muchas personas vinculadas a la promoción de las personas más desfavorecidas por su simplicidad, y por la necesidad de demostrar el compromiso social de las cajas en un momento de máximo crecimiento financiero de las mismas. Además, en aquel momento uno de los autores del presente artículo estaba asumiendo el encargo de impulsar el primer programa de microcrédito impulsado por una caja de ahorros en España, por Caixa Catalunya.

\footnotetext{
' Obra Social Caixa Catalunya <angel.font@fcaixacatalunya.es>.

2 Facultat d’ Economía IQS. UnIVERSITAT RAMÓN LIULL <carlos.moslares@iqs.es>.
} 
Es evidente que ambos movimientos, las cajas de ahorros y los microcréditos, han sido exitosos. Ambos han conseguido dimensiones y reconocimientos sin precedentes, como lo demuestra, por un lado, el hecho que las cajas de ahorros españolas ocupen una proporción mayoritaria en relación a los bancos comerciales en el mercado financiero español; y por el otro, la reciente concesión del Premio Nobel de la Paz 2006 al Profesor Muhammad Yunus, al Grameen Bank y por extensión a todo el movimiento de instituciones dedicadas al microcrédito en el mundo.

El presente trabajo recoge la investigación sobre el origen y la evolución de ambos movimientos, especialmente del primero, con la finalidad de compararlos y de establecer pautas comunes de análisis y predicción de sus actuaciones futuras, que podrían llegar a ser tan relevantes para la mejora de las condiciones de vida de millones de personas en todo el mundo.

\section{Las entidades de financiación inclusiva}

La construcción de sectores financieros incluyentes mejora las condiciones de vida de las personas, en particular las de los pobres. Un pequeño préstamo, una cuenta de ahorros o una póliza de seguros pueden hacer una gran diferencia para una familia de bajos ingresos. Permiten que las personas inviertan en mejor alimentación, vivienda, salud, y educación para sus hijos. Disminuyen la tensión de tener que soportar tiempos difíciles causados por fracasos en la cosecha, enfermedad o muerte. Ayudan a las personas a planear el futuro.

Kofi Annan (Naciones Unidas, 2006)

Con este claro mensaje el anterior Secretario General de Naciones Unidas encabezaba un ambicioso trabajo impulsado por varias agencias de las Naciones Unidas con la colaboración del resto de agencias multilaterales (Banco Mundial, Fondo Monetario Internacional, Fondo Internacional para el Desarrollo Agrícola y la Organización Internacional del Trabajo) con la finalidad de promover la creación de sistemas financieros inclusivos como paso imprescindible para la construcción de una sociedad mundial más equilibrada y sin los actuales niveles de pobreza. Este trabajo configuró el informe La construcción de sectores financieros incluyentes para el desarrollo, también denominado "Libro Azul" por su pretensión de devenir en documento de referencia para la próxima década a modo de "hoja de ruta" o plan director de las finanzas inclusivas mundiales. 


\section{I. Definición de entidad de financiación inclusiva}

La financiación inclusiva es un concepto nuevo que puede describir, como se demuestra a lo largo del presente trabajo, situaciones muy diversas tanto geográficamente, como muy distantes en el tiempo. En general, podemos definir las instituciones de financiación inclusiva como aquellas proveedoras de servicios financieros básicos (crédito, ahorros, seguros, remesas, transferencias,...) dirigidas a las personas con escasos ingresos y en situación de pobreza. Incluyen un amplio abanico de instituciones: ONG, bancos comerciales, instituciones financieras públicas, bancos postales, cajas de ahorros, cajas rurales, cooperativas de crédito, y otras instituciones financieras no bancarias, como las aseguradoras y las mutuas. Algunas de estas organizaciones son muy grandes; otras son muy antiguas.

El interés de las Naciones Unidas por la financiación inclusiva se basa en la extraordinaria capacidad de mejorar las condiciones de vida de centenares de millones de personas que hasta el momento han demostrado tener las microfinanzas y las instituciones dedicadas a los microcréditos en el Sudeste Asiático, en América Latina y Oriente Medio y en el África Subsahariana. El mismo informe señala que Una revisión reciente de las encuestas reportó que el $89,6 \%$ de la población en 15 países de la Unión Europea tenían una cuenta bancaria, con proporciones que van desde el 99,1\% en Dinamarca al 70,4\% en Italia. Una cifra comparable para los Estados Unidos fue del $91 \%$. Por el contrario las cifras recogidas para los países en desarrollo por el mismo informe de Naciones Unidas es el siguiente:

\section{TABLA I. Indicadores de exclusión financiera}

\begin{tabular}{|l|c|}
\hline \multicolumn{1}{|c|}{ País / Lugar } & $\begin{array}{c}\text { Porcentaje de población } \\
\text { con una cuenta corriente }\end{array}$ \\
\hline Botswana & $47 \%$ \\
\hline Brasil (urbano) & $43 \%$ \\
\hline Colombia (Bogotá) & $39 \%$ \\
\hline Sudáfrica & $32 \%$ \\
\hline Djibouti & $25 \%$ \\
\hline Ciudad de México & $21 \%$ \\
\hline Lesotho & $17 \%$ \\
\hline Tanzania & $6 \%$ \\
\hline
\end{tabular}

Fuente: Libro Azul, Naciones Unidas, 2006. 
Este informe defiende la existencia de una variedad de instituciones financieras, especialmente mutuas de crédito, cajas de ahorros, cajas rurales e instituciones microfinancieras, para incorporar a los más pobres al mercado financiero. Esta posición de las Naciones Unidas supone la irrupción de un nuevo aliado en el debate sobre el futuro de las cajas de ahorros españolas. En efecto, la discusión sobre la naturaleza jurídica de las cajas de ahorros españolas no es nueva, ya que diversos sectores en España e incluso en la Comisión Europea defienden su conversión en sociedades anónimas participadas por accionistas. De esta manera se evitaría el hecho que las cajas no puedan ser adquiridas por los bancos -argumentan-. Aunque, probablemente, provocaría su "desnaturalización social", como ya ha ocurrido en Italia y en el Reino Unido.

Este protagonismo de las instituciones microfinancieras es crucial en la consecución de los Objetivos del Milenio de reducir a la mitad la pobreza extrema del mundo, antes del año 2015. No es para menos, ya que si en la actualidad cerca de 1.000 millones de personas están en situación de pobreza extrema, unos 500 millones de éstas pueden verse favorecidas por programas de microcrédito en todo el mundo antes de esa fecha. Asimismo, las Naciones Unidas reclaman a los bancos centrales de todos los países que, además de velar por la protección de sus ahorradores y la estabilidad del sistema financiero, incorporen entre sus cometidos la mejora del acceso de los pobres y los microempresarios al mercado financiero.

Aunque el porcentaje de personas con acceso al sistema financiero en los países desarrollados es más alto que en el caso de países menos desarrollados, no deja de haber colectivos con difícil acceso. Por ejemplo, a pesar de la dificultad para medir el número de personas que pueden estar fuera del sistema financiero en España, existen estimaciones que indican que este colectivo es significativo. Aunque el porcentaje de españoles que dispone de, al menos, una cuenta corriente supera el 96 por ciento, algunos analistas consideran que entre un 5 por ciento y un 10 por ciento de la población española no tendría acceso al resto de servicios financieros considerados básicos, entre ellos el acceso al crédito (Carbó y López, 2005). Esta cifra seria suficientemente elevada como para plantear la necesidad de poner en marcha programas específicos de microcrédito en España.

A pesar de ello, nuestro nivel de exclusión financiera presenta registros sensiblemente inferiores a los de otros países de nuestro inmediato entorno. Esta situación podría explicarse en buena medida por la fuerte presencia de cajas de ahorros, y en menor medida, cajas rurales y cooperativas de crédito no agrarias en toda España, con una política de atención cercana que ofrece una red de oficinas en pequeñas localidades y en barrios que no tiene comparación con otros países. La 
excepcional situación que vive España, provocada por un incremento sin precedentes del número de personas inmigrantes que han llegado al país en los últimos años, está presionando al alza las situaciones de exclusión financiera.

Recientes estudios han realizado una aproximación cuantitativa a la contribución de las cajas de ahorros españolas a la reducción de la exclusión financiera (Valle, 2005). Ésta se calcula mediante tres factores. El primero es el mantenimiento de oficinas que operan en municipios potencialmente rescatados de la exclusión financiera en unos 1.200 municipios españoles, normalmente municipios de menos de 2.000 habitantes en entornos rurales. En segundo lugar, se calculan los servicios prestados en forma de crédito social, ya sea en forma de crédito prendario o en forma de microcrédito para el autoempleo. Finalmente, se considera la financiación de actividades de sensibilización social, como son la vivienda social o la financiación rural. Para el conjunto de las cajas de ahorros españolas, esta contribución superaba los 4.000 millones de euros en 2002.

Como se ha indicado, la realidad de exclusión financiera en países como el Reino Unido e Italia es todavía más desfavorable y la cifra de excluidos podría elevarse hasta el 15 por ciento o incluso el 30 por ciento de la población. Esto podría explicarse por su peculiar entorno financiero muy marcado por la concentración del negocio financiero en un número muy reducido de bancos, que en los últimos años han impulsado una política de reducción del número de oficinas -han cerrado las situadas en puntos más alejados o con menor nivel de renta- $y$ un incremento de los nuevos canales - por ejemplo, la banca por "Internet"- que no llegan a toda la población.

Paradójicamente, esta situación se da en países con una gran tradición de banca social-Inglaterra fue la cuna de las cajas de ahorros- que, como ya se ha indicado, han pasado en los últimos años por procesos progresivos de reforma que han desnaturalizado las cajas de ahorros hasta convertirlas en sociedades por acciones equivalentes a bancos y alejadas de su origen benéfico-social.

\subsection{Usura y exclusión financiera}

Aunque hoy definimos las practicas usurarias como la percepción de un interés excesivo, y por extensión de todas las situaciones de abuso en el uso de instrumentos de préstamo, no siempre se ha mantenido el mismo criterio. En España, la regulación medieval de la usura se configuraba a partir del entrecruzamiento de textos cristianos, musulmanes y hebreos, de carácter prohibitivo, en los que se 
fijaba un límite máximo del tipo de interés en el 12,5\%. Era tal la aversión de la época hacia el concepto de usura que el Rey Alfonso X llegó a "negar sepultura a usureros públicos", aunque, contradictoriamente, no limitó la práctica de la usura, con tipos de interés que podían llegar al 100\%. (Montero, 1983). Tradicionalmente la usura siempre ha tenido este tratamiento contradictorio. Por un lado, la Iglesia que había llegado a negar cualquier posibilidad de añadir un interés al capital prestado ${ }^{3}$, finalmente, opta por un camino práctico al afirmar que sólo la "usura opresiva" (aplicada al pobre) está condenada por la ley natural y divina no ocurriendo lo mismo con el préstamo de comercio ni la usura con los ricos ${ }^{4}$. Por el otro, las clases burguesas empezaron posicionándose, a partir de sus ideas liberales, a favor de la usura como fenómeno meramente económico, y acabaron justificando la aparición de las cajas de ahorros para contrarrestar la crisis social de la nueva era: El ahorro es esencialmente antirrevolucionario, asociando al proletario por medio de su propio trabajo al interés y a los goces de la propiedad y del orden ${ }^{5}$.

Las condiciones de la usura habituales de la época rondaban el 60\% de interés anual, (Montero, 1983) tal como reflejaba la publicación "La Emancipación" el $28 / 8 / 1871$ en la que se transcribe el texto que figura en el recibo expedido por los prestamistas: El dueño de los efectos empeñados se obliga voluntaria y solemnemente y de conformidad con lo que previene la Ley de 14 de Marzo de 1856, a satisfacer además del capital de empeño, el cinco por ciento mensual, por razón de interés, comisión y garantía.

Estas condiciones son mejores que las que todavía hoy en día vienen sufriendo millones de personas que viven en entornos financieros poco desarrollados. Recientemente se han descrito situaciones en las que se aplica el 10\% diario para crédito comercial en mercados de alimentación en Mozambique o 10\% mensual para créditos destinados a la aventura migratoria en América Latina (Font, 2006). Tampoco estaba muy alejada la situación que motivó el experimento socioeconómico que el Profesor Yunus desarrolló en 1976 en la aldea de Jobra y que posteriormente se convertiría en la base de su Grameen Bank. Yunus explica

\footnotetext{
${ }^{3}$ Todo lo que se añade al capital, llámese como se quiera, es usura. La usura es en si ilícita. En este punto soy de la misma opinión que la Iglesia. Yo llamo robo al interés. Instrucción del Obispo de Salamanca (1875)

${ }^{4}$ Montero cita el abate italiano Marco MASTROFINI, autor de Tratado de la Usura (1859)

${ }^{5}$ Montero cita a Ramón de Mesonero Romanos en Diario de avisos (1835) como uno de los mentores de las cajas de ahorros en España
} 
que prestó 27 dólares de su bolsillo a 42 mujeres artesanas que confeccionaban taburetes de mimbre, tras comprobar que para desarrollar su trabajo sólo tenían la opción de pedir préstamos a los usureros al 10\% mensual, o pedir anticipos a los intermediarios que luego les comprarían los taburetes, con la consiguiente reducción de su precio. En aquella época el trabajo de todo un día de confección de taburetes les rendía unos 50 "poishas", apenas 2 centavos de dólar. El acceso al microcrédito multiplicó por 20 sus beneficios, todavía exiguos. (Yunus, 1997). Treinta años más tarde, en 2006, Grameen Bank disponía de 7 millones de clientes a los que ofrecía microcréditos por un valor superior a los 600 millones de dólares americanos. (Lacalle y otros, 2007).

\section{La Evolución de las cajas de ahorros y montes de piedad desde el siglo XVI hasta la actualidad}

\section{I El préstamo prendario y los montes de piedad}

La historia de las instituciones de financiación inclusiva europeas se remonta a la Edad Media, momento en el que aparecen diversas figuras, normalmente vinculadas a la Iglesia Católica, en las que se reflejan algunos de los elementos benéficos que persiguen la promoción social de las personas más vulnerables de aquella sociedad, es decir, de la mayoría.

En España, las más antiguas fueron las llamadas Arcas de Limosnas ${ }^{6}$, instituciones fundadas por el Conde de Haro en diversas ciudades de Castilla, como Burgos, Logroño o Palencia. Su funcionamiento está confirmado (Yepes, 1973) ya que así lo refleja la Bula, otorgada por el Papa Eugenio IV en 1431: que para el socorro perpetuo de pobres y personas necesitadas había erigido don Pedro Fernández de Velasco en las Iglesias Parroquiales de Medina de Pomar, Briviesca, Villadiego, Herrera, Salas, Belorado, Arrendó y Risaleña,... con la dotación de 11.560 florines de oro. Las principales características de estas incipientes instituciones son su orientación social y la lucha contra la usura: luchar contra el pecado detestable

\footnotetext{
${ }^{6}$ A finales del siglo XVI también aparecieron en España los Erarios Públicos, promovidos por el flamenco Pedro de Oudegherste con el objetivo de llenar las arcas del Tesoro y, adicionalmente luchar contra la usura. Funcionaron durante el reinado de Felipe II y tenían más de banco público que de institución civil, aunque con objetivos y maneras muy parecidos a los montes e incluso a lo que más tarde serian las cajas de ahorros.
} 
de las usuras y renuevos y socorrer a las necesidades de los menesterosos (Yepes, 1973). La mecánica de sus préstamos era simple: créditos sin interés, sobre prendas o garantías seguras, por un plazo no superior a un año, y reintegrando en el primer cuatrimestre, al menos, una cuarta parte de lo prestado. En caso de impago, se producía la venta forzosa de la prenda.

Durante el siglo XV también se constituyeron otro tipo de instituciones con similar orientación, pero con diferente método. El préstamo no se realizaba en efectivo sino en especie, normalmente granos y semillas para la producción agrícola y su desarrollo está especialmente centrado en Castilla. Estas instituciones tuvieron diversos nombres y formas aunque los que han podido quedar descritos por los historiadores son los pósitos y las arcas de misericordia.

A pesar de estos relevantes antecedes, el concepto de monte de piedad que ha llegado hasta nuestros días responde a la innovación que introdujeron los franciscanos Fray Bernabé de Terni y Fray Miquel Carcano al instituir el primer monte de piedad en la ciudad de Perugia, Italia, en 1462. Tan sólo 30 años después de la creación del Monte de Piedad de Perugia, ya se habían creado 83 montes de piedad en otras tantas ciudades italianas.

Los montes de piedad van apareciendo en cada ciudad de una forma parecida: se constituye un fondo patrimonial que suele estar constituido por una combinación de donaciones con depósitos sin interés. Uno de los debates generados en aquella etapa inicial de los montes de piedad fue la oportunidad de aplicar un tipo de interés reducido a los préstamos, ya que hasta el momento se prestaba sin interés. Finalmente, la polémica fue zanjada en el Concilio de Trento, en el que se aceptó la posibilidad de aplicar tipos de interés reducidos a los préstamos de los montes de piedad.

La fama de los montes de piedad llegó a España con un cierto retraso, ya que las primeras instituciones que toman esta denominación se remontan a la primera mitad del siglo XVII, ciento cincuenta años después que naciera el Monte de Piedad de Perugia. En 1626, se creó el Monte de Piedad del Hospital de Nuestra Señora de Gracia en Zaragoza, mediante la capitalización de bienes intestados de los enfermos del hospital que morían. Pero no fue hasta principios del siglo XVIII que la idea de los montes de piedad no toma fuerza en España, tras la creación del Monte de Piedad de Madrid en 1708. Esta institución fue promovida por el padre Francisco Piquer y Rudilla, quien, emulando al Beato Bernardino de Feltre, destinó prácticamente toda su vida a la creación del Monte y sus réplicas. El capital del Monte se constituyó mediante: rentas reales provenientes de las Indias; legados 
y herencias; limosnas, y depósitos. Los depósitos a coste cero crecieron mucho, y jugaron un papel precursor de lo que más tarde serían las cajas de ahorros.

El Monte madrileño, por su desarrollo y ubicación, marcó las pautas para el posterior desarrollo de los montes de piedad en España. En 1728 aparece el Monte de Piedad de Salamanca que, al principio, funcionaba con préstamos sin interés, aunque más tarde tuvo que imponer un $5 \%$ en los préstamos al tener que retribuir los depósitos. En 1731 se creaba el Monte de Piedad de Zaragoza. En 1741 el Monte de Piedad de Santa Rita de Casia de Granada era fundado por don Isidro Antonio Sánchez, presbítero de Granada, devoto de Santa Rita de Casia, que recibe la influencia del Padre Piquer y del Monte de Madrid. Su desarrollo fue muy rápido ya que en 1763 el Monte ya atendía a unas 15.000 personas (Roca, 1968).

El Monte de Piedad de Nuestra Señora de la Esperanza de Barcelona fue fundado en 1749 por la Congregación de Nuestra Señora de la Esperanza y Salvación de las Almas en un momento de crisis económica y social de la Barcelona de mitad del siglo XVIII y como especial respuesta a esta situación (Voltes, 1965)7.

\subsection{Las cajas de ahorros y la aparición de mecanismos financieros de pro- tección social}

Los montes de piedad surgieron como una idea transformadora en un momento de cambio social acelerado, como fue el Renacimiento italiano. También las cajas de ahorros surgen como respuesta a una nueva situación, la de las mayorías asalariadas y proletarias que aparecen en la Revolución Industrial. A principios del siglo XIX, en Alemania, en el Reino Unido y también en Francia, se van desarrollando diferentes iniciativas con objetivos sociales todavía muy heterogéneos, que van desde la lucha contra la pobreza, la protección del ahorro de los trabajadores o el combate de la usura. Propiamente la aparición de las cajas de ahorros ha sido considerada como la síntesis del pensamiento social y político de la época, que se debatía entre la necesidad de introducir altas cotas de libertad de mercado y las dificultades que propiciaban las grandes desigualdades generadas por el sistema. Las cajas de ahorros pretendían independizar a los trabajadores de la beneficencia

\footnotetext{
${ }^{7}$ En el hecho concreto de la fundación de los Montes de piedad podemos identificar en éstos un instrumento de salvaguardia de los valores poseídos por las clases modestas; aunque fuera débil y parcialmente, los Montes ejercieron de dique amortiguador de la tremenda presión desvalorizadora que pesaba especialmente sobre las clases que no podían reponer sus limitados activos, y salvaron para éstas una serie de bienes que la subida de precios hubiera arrastrado cauce abajo, Voltes, 1965.
} 
pública, para hacer frente a los problemas generados por el desempleo, la enfermedad o los accidentes laborales (Almenar, 2003). Las primeras cajas aparecen en ciudades industriales: Oldenburg, Alemania (1786); Tottemham, Inglaterra (1798); Ruthwell, Escocia (1810); Holsteinborg, Dinamarca (1810); Liverpool, Inglaterra (1815); Haarlem, Holanda (1817); Paris, Francia (1818) y se extienden rápidamente por toda la Europa liberal.

En España no será hasta bien entrado el segundo tercio del siglo XIX que aparezcan las primeras cajas, debido al retroceso político derivado de la Guerra de la Independencia (1808-1814) y la restauración absolutista, y que acabó con la ilusión de instaurar un sistema político liberal homologable al resto de los estados europeos que significaba la Constitución de 1812.

Los mecanismos de protección social de la época eran claramente insuficientes para contener las nuevas necesidades sociales: en 1860, dos tercios de la población española vivía en el campo (Morales, 2003) en un contexto de rápida migración hacia las ciudades; la esperanza de vida de un miembro de la burguesía era de 34 años, mientras que la de un proletario no alcanzaba los 20 años (lzard, 1978)

En este contexto de revolución liberal y transformación socio económica (pérdida de las Índias, reforma agraria, industrialización...), el sector bancario se centra en las capitales, especialmente en Madrid, y está basado en el comercio, sin prestar atención alguna a las clases populares (Tedde de Lorca, 2003). Así, cuando Diego Medrano y Treviño es nombrado Ministro de Interior en 1835 se fija como principal prioridad la creación de las cajas de ahorros en España, redactando personalmente la Real Orden de 1835 para la creación de las cajas, desde unos planteamientos liberales, solicitando a cada gobernador civil que excite a los pudientes, o ponga los medios que según las circunstancias de esa provincia sean adecuados para establecer en ella Caja o Cajas de ahorros... Lagares y Neira han analizado a fondo el personaje y su decreto para deducir lo que ellos denominan, "el programa Medrano" para el fomento de las cajas de ahorros (Lagares y Neira, 2003). Este programa se resume en 6 puntos que bien podrían ser asumidos por cualquiera de las instituciones de financiación inclusiva que proponen las Naciones Unidas para el siglo XXI:

a) Fomento del ahorro popular: Algunos pueblos cultos han sustituido ventajosamente a los medios adoptados antes para establecer la moral y mejorar la condición de las clases industriosas ciertas cajas de ahorros, donde el menestral yel jornalero, y todo hombre laborioso puedan depositar sumas muy tenues bajo la confianza de obtener un rédito proporcionado, de capitalizar los intereses en cortos periodos, y de realizar sus fondos en todo tiempo. 
b) Prevención de la exclusión social: cuando semejantes instituciones prestan garantías seguras, constituyen en gran manera a propagar el espíritu de economía, y con él, la propensión al trabajo; a desterrar los vicios, y con ellos, las enfermedades y delitos de que son gérmenes.

c) Orientaciones para la inversión del ahorro hacia actividades productivas en el ámbito privado: mientras no se recupere el crédito público y sean los fondos públicos el asilo seguro y ventajoso de los ahorros del pobre.

d) Mantenimiento del Ahorro a la vista para aumentar la seguridad: que la seguridad de los fondos depositados es, entre las condiciones que este género de establecimientos requiere, la más esencial para su feliz éxito.

e) Implicación de los impositores en la gestión de las cajas: para conseguir la imprescindible condición de inviolabilidad de estos fondos, como elevados a la clase de propiedad particular, libres de las invasiones de la autoridad particular bajo pretexto de préstamos forzosos $\mathrm{u}$ otros semejantes medios.

f) Combinación entre montes de piedad y cajas de ahorros para luchar contra la usura: la ejecución de este filantrópico pensamiento, ha dado un golpe mortal y bien justamente merecido a los explotadores de la miseria pública, a los crueles usureros.

Tres años más tarde se funda la primera caja en España, la Caja de Ahorros de Madrid (1838), impulsada por Joaquín Vizcaíno, Marqués de Montejos y Gobernador de Madrid y por Ramón de Mesonero Romanos, escritor e intelectual, aprovechando la influencia de la Sociedad Económica Matritense de Amigos del País. Nació ya con una estrecha vinculación al Monte de Piedad de Madrid. Prestaba los ahorros al Monte al 5\%, mientras retribuía a los imponentes con un $4 \%$. Esta alianza era un resultado natural: ... pues mientras la caja por su propio crédito y por el instinto de economía y moralidad que ha sabido inspirar a todas las clases, aumenta y aumentará indefinidamente sus ingresos, el Monte, estacionado en sus operaciones de empeño de alhajas se ve más y más apurado para dar salida a sus fondos ordinarios... de tal modo que sean infinitamente mayores las ventajas atrayendo en consecuencia nuevos gérmenes de vida y de prosperidad a aquel Establecimiento (El Monte), al paso que permitan desarrollarse a su sombra a su natural hermana la Caja de Ahorros (De Mesonero Romanos, R., 1851).

En los años siguientes se crean varias cajas de ahorros, la mayoría de ellas asociadas a montes de piedad: Santander (1841), Granada (1841), Sagunto (1841), Valladolid (1841), Sevilla (1842), Barcelona (1844), Burgos (1845), Vitoria (1856), 
Jerez de la Frontera (1859), Sabadell (1859), Laietana, Mataró (1863), Málaga (1863), Girona (1864), Manresa (1865), Córdoba (1878), Alcoy (1875), Zaragoza (1876), La Coruña (1876), Terrassa (1877), Segovia (1877), Valencia (1878), Ávila (1878), Linares (1879), Orihuela (1879), San Sebastián (1879), Pontevedra (1879), Santiago (1880), Palma (1882), Cádiz (1884), Onteniente ((1884), Segorbe (1884), Valladolid (1885), General de Granada (1893), Provincial de Guipúzcoa (1896), Manlleu (1896), León (1900), Castellón (1900), El Ferrol (1902), Badajoz (1910), Novelda (1903)...

En aquellos primeros años, el reparto regional del número y el peso de las diferentes cajas de ahorros es bastante homogéneo, aunque destaca el liderazgo de las cajas andaluzas, junto con el conjunto de cajas catalanas. Ello se debía al dinamismo cívico en algún caso e industrial en otros, presentes en estos territorios y que impulsaba la creación de cajas, en una mezcla entre altruismo y mantenimiento del statu quo, para evitar disturbios sociales (Petit, 1967).

Voltes también se refiere al móvil de la paz social, que queda reflejado en la moción aprobada el 24 de abril de 1839 en el Ayuntamiento de Barcelona para el impulso de la caja de ahorros barcelonesa (Voltes Bou, P, 1965).

En efecto, el conjunto de cajas de ahorros catalanas fueron creciendo en captación de ahorros durante esos años, hasta alcanzar en 1874 depósitos por importe superior a los 16 millones de pesetas (Titos, 2003). Estos fondos fueron alimentando de recursos a los montes de piedad, en los casos que existía tal asociación, o se canalizaban hacia determinadas necesidades de crédito originado por el crecimiento de las ciudades manufactureras, en el caso de no contar con monte de piedad.

El perfil de la clientela de las cajas de ahorros y montes de piedad en la segunda mitad del siglo XIX muestra un claro sesgo de género y fue mayoritariamente femenina (Martínez, 2003). Según Martínez, también tuvieron mucha importancia los grupos laborales de los trabajadores del servicio doméstico y los jornaleros. En Cataluña, de forma peculiar, la presencia de trabajadores industriales es mayor, y también de comerciantes y pequeños industriales.

A pesar de la voluntad pacificadora de los fundadores de las cajas, la segunda mitad del siglo XIX sigue pendiente del conflicto social entre clases. A principios del siglo XX, la lucha obrera se intensifica en medio de un contexto de fuerte tensión social: revuelta de Cuba, guerra con los Estados Unidos, crisis política y económica, paralización de los mercados, generalización del paro obrero. Estudios sobre la situación de la clase obrera de la época concluyen que donde trabaja 
una sola persona es imposible que se atienda, ni de mucho, el buen estamento de mujer y dos hijos. Para ir bien, debían trabajar padre, madre e hijo mayor, y aún dedicando el 75\% de los ingresos a la manutención (Pérez-Bastardas, 1999). Tras las huelgas de 1901 y 1902, primero en la cuenca textil del Ter, y más tarde en Barcelona, la situación se hace insostenible: cierre patronal, miles de trabajadores en paro, paralización de la elaboración del pan, enfrentamientos violentos que se saldan con 200 detenidos, 50 heridos graves y 14 fallecidos.

En este contexto aparece una figura clave en el desarrollo futuro de las cajas en Cataluña y España: Francesc Moragas, a quien muchos califican como un punto de inflexión en la historia de las cajas y, muy especialmente, del movimiento de protección social que dará lugar a lo que hoy conocemos por estado del bienestar (Riera, 2005). Moragas era un abogado muy marcado por las ideas del catolicismo social, el catalanismo político y la implantación de los seguros como mecanismo de promoción social.

Moragas introduce un pensamiento que hoy podríamos calificar de muy poco paternalista, muy alineado con algunos de los actuales postulados sobre la inclusión social: Sólo hay una persona que pueda preservar del pauperismo al obrero, y es el obrero mismo. Nadie ignora que las tres principales causas de pauperismo son la enfermedad, la vejez y la muerte. Aboguemos por la caridad, pero no olvidemos la previsión, no sea el caso que al ser examinados nuestros actos pueda decirse de nosotros que hemos sido muy caritativos para socorrer desdichas producidas por nuestra mismas injusticias sociales (Moragas, 1898).

A principios del 1902, Moragas propone la creación de la Caja de Pensiones para la Vejez con el apoyo del Fomento del Trabajo (la patronal catalana), diputados provinciales y los presidentes de Sociedades Económicas.

Su proyecto se basa, inicialmente, en una crítica al impacto social reducido que habían conseguido las cajas de ahorros y los montes de piedad: La influencia aislada y raquítica de los Montepíos y Cajas particulares, que con muy buena voluntad fundan personas merecedoras de entusiasta aplauso por sus sentimientos benéficos, pero que carecen de estabilidad y solidez por no haberse fundamentado en bases técnicas aceptables, constituyen viva amenaza para el porvenir de un problema de gran trascendencia, que con dichos Montepíos ha sido mal planteado. El legislador, el Estado y cuantas entidades y personas se interesan a favor de la buena organización de las pensiones para la vejez, han de estudiar decididamente la manera de lograr que dichos Montepíos puedan ser ventajosamente sustituidos por las "Cajas de pensiones para la vejez", organizadas técnicamente, respetuosas 
de la tablas de mortalidad y de cuantos principios económicos y financieros son necesarios para garantizar el éxito de esta operaciones (Moragas, 1902).

Nace así la Caja de Pensiones para la Vejez y de Ahorros. Sus primeros productos son: la pensión diferida, fondo compuesto de aportaciones libres y con capacidad de rescate anticipado; la pensión vitalicia, próxima a la pensión pública actual; y los capitales diferidos, normalmente utilizados para dotes de mayoría de edad.

Simultáneamente a la creación de la Caja de Pensiones, el Ministerio de Trabajo gesta la creación del Instituto Nacional de Previsión, antecesor del actual Instituto Nacional de Seguridad Social español. Moragas participa activamente en su gestación, y lo aprovecha para conseguir un convenio de colaboración, en exclusiva para Cataluña y Baleares, para la recaudación de los seguros, inicialmente voluntarios, en nombre del Estado. Este convenio le reportará una posición de ventaja competitiva, todavía reforzada unos años después, con el establecimiento de la obligatoriedad de los seguros de pensiones para todos los trabajadores entre los 16 y los 65 años.

A partir de este momento todas las cajas de ahorros catalanas crecen a un ritmo elevado. En 1915, la Diputación de Barcelona inicia las acciones para fundar su propia caja de ahorros aunque no se materializa hasta 1926, con la creación de la Caja de Ahorros Provincial de la Diputación de Barcelona, que más tarde pasaría a denominarse Caixa Catalunya y que llegaría a ser la segunda entidad de ahorros catalana. Una de las principales motivaciones que provocaron su creación fue el facilitar la contribución de la Diputación, y crear, de esta manera, los pilares de lo que más tarde sería un sistema moderno de recaudación de impuestos para financiar el estado del bienestar. En palabras de Francesc Roca, Caixa Catalunya no nació como caja de familias, sino como caja de contribuyentes. Sin embargo, muy rápidamente quiso llegar a ser una caja general de ahorros (Roca, 2001).

Pronto, diferentes regulaciones acentuarán el carácter financiero de las cajas, en detrimento del perfil benéfico-social. A partir de los años veinte, durante el periodo de la dictadura de Primo de Rivera, se inicia la utilización obligatoria de una parte cada vez mayor de recursos captados por las cajas como fuente de financiación privilegiada de la política inversora del Estado. La Segunda República supuso en Cataluña una ampliación de las competencias en política de seguros sociales que reforzaron todavía más el carácter financiero de las cajas catalanas y reconocieron su carácter previsor. Este reconocimiento fue tan intenso como fugaz, debido al golpe de estado y posterior guerra civil, que trunca la positiva evolución que las cajas de ahorros habían tenido hasta el momento. 
Durante la dictadura franquista se incrementa la intervención pública, hasta alcanzar la utilización obligatoria por parte del Estado de niveles superiores al $85 \%$ de los recursos disponibles (Torres, 2005). En paralelo, y debido al crecimiento de los ahorros captados, la rentabilidad también aumenta, y con ella, la proporción de beneficios que puede aportarse a la obra social. Ésta tiene durante las décadas de los 50, 60 y 70 un marcado carácter de sustitución del Estado en materias como: educación, sanidad, formación profesional, bibliotecas, vivienda social, residencias de ancianos,...

\subsection{El éxito financiero de las cajas de ahorros}

A principios de los años 70 del pasado siglo, el sistema financiero español, en general, y el sector de las cajas de ahorros, en particular, era uno de los más rígidos y con mayores restricciones para desarrollar su función financiera. Por ello, a partir de 1977, con la llegada de la democracia, se inicia un profundo proceso de reforma y liberalización y que daría paso, entre muchos otros aspectos, a la equiparación funcional de cajas y bancos (Cals, 2005).

Las cajas mostraron una elevada capacidad de adaptación a este nuevo entorno, y especialmente, una capacidad competitiva que no habían mostrado hasta el momento. En cualquiera de las variables que se analicen, las cajas han ganado terreno en relación a los bancos en los últimos 30 años. El porcentaje de recursos ajenos gestionado por las cajas en relación a los recursos gestionados por el conjunto del sistema financiero español ha pasado del $30 \%$ en 1974 hasta el $49 \%$ en 2004; los créditos concedidos, del 18\% en 1974 al 45\% en 2004 (CECA, 2008).

Entre las causas que explican esta estrategia exitosa se pueden citar: la territorialidad de las cajas que les asocia a valores de cercanía y confianza, el dinamismo comercial entre particulares y empresas, la apuesta tecnológica que potenció su competitividad y la cooperación entre cajas.

Cabe destacar que toda esta transformación económica y financiera, se ha llevado a cabo sin afectar sustancialmente la naturaleza jurídica de las cajas de ahorros, que mantiene su formato fundacional.

Esta peculiar naturaleza jurídica alimenta permanentemente el debate sobre la posible conversión de las cajas a sociedades de capital, bajo el discutible argumento de la asimetría en las relaciones de mercado entre entidades financieras, ya que las cajas pueden comprar bancos y los bancos no puedan comprar cajas. 
Riera analiza a fondo esta cuestión y concluye que existe un elevado peligro de pérdida del carácter social y no lucrativo de las cajas si éstas se transformasen en sociedades de capital.

Riera cita el Reino Unido como un caso "especialmente aleccionador" al tratarse de la cuna de las cajas de ahorros europeas, tal como se ha explicado más arriba. En 1983 se trasforman en sociedades anónimas. Tres años más tarde, todas las cajas que todavía no habían desaparecido y sus sociedades filiales se integraron en una única sociedad mercantil que cotizaba en Bolsa, la Trustee Savings Banks Group (TSB Group). En la actualidad, las acciones están en manos del Lloyds Bank. (Riera, 2005).

Así pues, el presente y el futuro de las cajas de ahorros parece estar bien enraizado en una larga historia que le aporta una identidad y valores muy actuales, y a su vez, basado en una solvencia institucional que le permitirá afrontar los nuevos retos de la sociedad que las apoya.

\section{Las Instituciones de microcrédito y las microfinanzas}

Las microfinanzas que surgieron como experimentos más o menos exitosos en los años 1970 se han convertido en una industria de dimensiones globales. Miles de organizaciones en todo el mundo movilizan miles de millones de dólares hacia las microfinanzas. Además de las propias organizaciones microfinancieras, se han creado numerosas empresas y organizaciones que les ofrecen servicios de consultoría organizativa o de desarrollo informático. Las agencias públicas de cooperación al desarrollo de muchos gobiernos donantes han creado sus departamentos y unidades especializadas, y muchas instituciones sociales privadas apuestan por las microfinanzas para canalizar su filantropía.

\section{I. Las etapas en la evolución de las instituciones Microfinancieras}

Rodríguez-Ferrera estableció tres etapas en la evolución de los programas de microcrédito desde sus inicios. 


\section{TABLA 2. Evolución de las Instituciones Microfinancieras}

\begin{tabular}{|l|l|l|l|}
\hline \multicolumn{1}{|c|}{ Etapa } & $\begin{array}{c}\text { 1960-1979 } \\
\text { Pequeños créditos } \\
\text { agrícolas }\end{array}$ & $\begin{array}{c}\text { 1980-1999 } \\
\text { Instituciones } \\
\text { microfinacieras }\end{array}$ & $\begin{array}{c}\text { 2000-2005 } \\
\text { Instituciones } \\
\text { reguladas }\end{array}$ \\
\hline Socios & Proyectos /ONG & Instituciones & Sistema financiero \\
\hline Servicios & Crédito & Crédito y ahorro & Servicios financieros \\
\hline Ahorro & No hay capacidad & Sí hay capacidad & $\begin{array}{l}\text { Ahorro externo e } \\
\text { interno }\end{array}$ \\
\hline Carencias & Capital físico & Eficiencia & Tecnología \\
\hline Estrategia & $\begin{array}{l}\text { Subsidio } \\
\text { microempresas }\end{array}$ & $\begin{array}{l}\text { Subsidio } \\
\text { instituciones }\end{array}$ & $\begin{array}{l}\text { Rentabilidad } \\
\text { alternativa }\end{array}$ \\
\hline
\end{tabular}

Fuente: Rodríguez-Ferrera, 2006.

a) Etapa 1960-1979. Pequeños créditos agrícolas: fase de introducción de los microcréditos a través de proyectos de ONG, financiados a través de donaciones, lo que permitía subsidiar los microempresarios con tasas de interés menores a los costes reales.

b) Etapa 1980-1999. Instituciones microfinancieras: crecimiento exponencial de los programas de microcrédito. De beneficiarios a clientes; tendencia a la sostenibilidad, se inicia la captación de ahorros para financiar la demanda de crédito. Se trasladan los costes a las tasas de interés.

c) Etapa 2000-2005. Instituciones microfinancieras reguladas: la creciente actividad financiera, provoca que los diferentes Estados adapten su legislación para regular este nuevo tipo de institución financiera.

En los últimos años han aparecido diversos fondos de inversión que operan fundamentalmente en los Estados Unidos y Europa que se han especializado en inversiones dirigidas a un tipo de instituciones microfinancieras que generan una rentabilidad suficiente para la sostenibilidad de esos fondos. Por su parte, numerosos bancos comerciales se muestran cada vez más activos en el terreno de las microfinanzas, especialmente en las regiones más rentables, como la Europa del Este y América Latina. 


\subsection{Las metodologías del microcrédito}

Las metodologías microfinancieras utilizadas a lo largo de los últimos treinta años se pueden agrupar en tres bloques:

a) Préstamos individuales: créditos solicitados por una sola personas, con garantía personal y/o prendaria, normalmente destinados al autoempleo y la microempresa, para la adquisición de activos fijos. Sus montos varían entre los 500 y los 2000 dólares.

b) Préstamos solidarios o grupales: los créditos son solicitados por un grupo de 3 a 10 personas, del que responden solidariamente. El grupo suele estar conformado por personas de la misma comunidad, ya que requiere de alto nivel de confianza y apoyo mutuo entre los miembros. Esta metodología fue implementada por primera vez en Bangladesh, por el Grameen Bank.

c) Bancos comunales: un modelo de crédito desarrollado por John Hatch, fundador de FINCA, una de las instituciones líderes en microcréditos en América Latina. Son asociaciones informales de entre 15 y 40 miembros, que se organizan con la finalidad de gestionar ahorros y créditos en zonas rurales de difícil acceso para las instituciones microfinancieras. Son estas instituciones las que prestan un capital inicial y una formación, y a partir de ahí, el grupo gestiona sus finanzas.

A pesar que las tres metodologías se han utilizado ampliamente, los grupos solidarios representan la apuesta más representativa de la adaptación a las realidades que envuelven los microcréditos. Desde un punto de vista relacional, el crédito grupal favorece la interacción de mujeres que viven de forma aislada y para entornos culturales en los que la mujer suele disponer de poca autonomía. Se conforma un grupo de ayuda mutua que, en condiciones de precariedad, suele resultar de gran utilidad y clave para la supervivencia de muchos pequeños negocios. El crédito grupal también consigue vencer la inercia de muchas mujeres por no tener una actividad propia fuera del hogar. Al realizar la actividad del crédito junto a otras personas que viven una situación similar a ellas, se vencen barreras naturales a la participación social.

\subsection{La globalización de las microfinanzas}

Se ha vivido una dinámica que tiende a cerrar la fractura de la exclusión financiera. Por un lado, las ONG y otras organizaciones microfinancieras que identificaron 
los microcréditos como estrategias de inclusión social y de erradicación de la pobreza, están adaptando sus iniciales metodologías de crédito grupal hacia nuevas fórmulas más sostenibles (Rodríguez-Ferrera, 2006), y con ello están aumentando progresivamente su tamaño conformando conglomerados empresariales que afectan a más de un país. Este fenómeno se ha descrito como "upscaling" o graduación de estas instituciones hacia un nivel superior de servicios financieros, en el que muchas de estas organizaciones operan bajo la regulación de los bancos centrales de cada país, y por tanto tienen consideración de bancos.

Por el otro, los bancos comerciales que operan en países con niveles de exclusión financiera elevados, han visto que las nuevas técnicas aplicadas por las instituciones microfinancieras permiten ampliar su propia base de clientes al incorporar, progresivamente, niveles inferiores de renta entre su público objetivo. Por ello, se han indicado numerosos programas de financiación a microempresarios por parte de bancos comerciales. Este proceso se ha descrito como "downsizing" o de reducción de tamaño.

Este continuo de servicios no es exclusivo para el acceso al crédito (Lacalle, 2002) sino que implica especialmente la movilización de los ahorros, la creación de nuevos sistemas de seguros y sistemas de previsión social, e incluso la provisión de otros servicios financieros complementarios, como el envío de remesas internacionales. Una encuesta realizada entre clientes del Grameen Bank, en Bangladesh, indicaba que los dos principales motivos para desear una cuenta de ahorro eran la futura compra de tierra y la seguridad para eventuales contingencias futuras. (Dowla y Barua, 2006)

Esta visión global sitúa el sistema microfinanciero como un enorme conector entre una gran cantidad de personas sin acceso hacia los sistemas financieros normalizados. Ésa sería la principal misión de este sector. Las estadísticas y las cifras indican que todavía se está muy lejos de conseguirlo, pero si se mantienen los niveles de crecimiento de los últimos años, no es inimaginable que se pueda completar en una fecha cercana.

Para que todo ello sea posible se deben seguir cumpliendo tanto los objetivos sociales como los económicos de las microfinanzas. Su principal reto es conseguir la sostenibilidad financiera sin abandonar su razón de ser, la inclusión de colectivos que viven en situaciones de pobreza. Sin sostenibilidad no hay crecimiento y sin éste no se pueden plantear la elevación de cuotas de mercado que alcancen a la mitad de la población excluida del planeta. Y para su sostenibilidad los tipos de interés tienen que recoger los costes financieros. 


\subsection{El microcrédito en la Europa del bienestar}

En Europa, el microcrédito llegó por el Este. Tras la caída del muro de Berlín (1989), se comenzaron a implementar actividades microfinancieras en los antiguos países comunistas con la finalidad de proporcionar un apoyo económico a aquellas personas que trataban de desarrollar actividades económicas generadoras de ingresos, en un entorno económico en el cual el sector bancario era incapaz de responder adecuadamente a las crecientes necesidades financieras de sus ciudadanos.

En los últimos años, las instituciones microfinancieras de la Europa del Este, de la Europa Central y de los nuevos países independientes han beneficiado, mediante pequeños préstamos, a más de 1,7 millones de pequeños empresarios y a más de 2,3 millones de ahorradores, lo que representa un crecimiento anual promedio del 30\% (Nowak, 2000).

En Europa Occidental, las microfinanzas aparecen ante todo como una herramienta de crecimiento económico y de cohesión social, de una manera parecida a como el Grameen Bank exportó su idea a los barrios necesitados de Chicago (Counts, A., 1996).

Para alcanzar estos objetivos, las microfinanzas en Europa Occidental deben acompañarse de otras medidas de acompañamiento empresarial, de desarrollo comunitario o de servicios sociales, y contar con circuitos bancarios y crediticios adaptados (López y Rodero, 2007).

\subsection{El microcrédito y los Objetivos del Milenio}

En 1997, se encontraron más de 2.900 personas de 137 países en Washington para celebrar la primera Cumbre Mundial del Microcrédito. En aquel momento se contabilizaron unos 7,5 millones de clientes de microcrédito en todo el mundo, de los cuales más de la mitad se situaban en Bangladesh, fruto de los exitosos programas del BRAC y el Grameen Bank. Los delegados de esa cumbre lanzaron un ambicioso reto: alcanzar las 100 millones de familias en la pobreza extrema a través de créditos para el autoempleo antes del final de 2005. Pocos pensaron que ese ambicioso objetivo se conseguiría.

La elección del 2005 como Año Internacional del Microcrédito por parte de las Naciones Unidas fue un hito importantísimo, pero no el único. Ha conseguido la implicación de grandes personalidades mundiales en la movilización de recursos 
para la campaña: jefes de estado, mandatarios de organismos multilaterales, filántropos, artistas y monarcas.

Desde el 12 al 15 de noviembre de 2006, más de 2.000 delegados de cerca de 200 países se reunieron de nuevo. Esta vez fue en Halifax, Nueva Escocia, Canadá, en la Cumbre Global de Microcrédito, para conocer el avance logrado hacia la meta de la Cumbre de alcanzar a 100 millones de las familias más pobres. Los objetivos se cumplieron razonablemente: hasta diciembre de 2005 se habían contabilizado cerca de 95 millones de familias en situación de pobreza extrema que ya participaban en programas de microcrédito. La cumbre de Halifax también fue el escenario para lanzar la segunda fase de la Campaña, con dos nuevas metas:

1) Asegurar que 175 millones de las familias más pobres del mundo, especialmente las mujeres de esas familias, estén recibiendo crédito para autoempleo y otros servicios financieros y empresariales para fines del año 2015.

Con un promedio de cinco individuos por familia, esto afectará a 875 millones de personas.

2) Asegurar que los ingresos de 100 millones de las familias más pobres del mundo asciendan de menos de US \$1 diario, ajustado a la paridad del poder adquisitivo (PPA), a más de US \$1 diario ajustado a la PPA para fines del año 2015.

Con un promedio de cinco individuos por familia, esto significará que más de 500 millones de personas habrán aumentado sus ingresos por encima de un dólar diario, casi completando una de las metas de Desarrollo del Milenio, la de reducir a la mitad la pobreza absoluta.

\section{Modelo evolutivo para las entidades de financiación inclusiva}

Del repaso histórico y de la comparación entre los dos movimientos analizados - cajas de ahorros y microcréditos- se puede deducir un modelo evolutivo común para los dos. La definición de este modelo evolutivo se basa en las necesidades sociales que atiende cada tipo de entidad, en cada periodo de tiempo analizado. El modelo establece 4 etapas acumulativas de crecimiento y transformación, a partir de los productos y servicios que en cada momento histórico van ofreciendo. 


\section{GRÁFICO I. Modelo Evolutivo de las Entidades de financiación inclusiva}

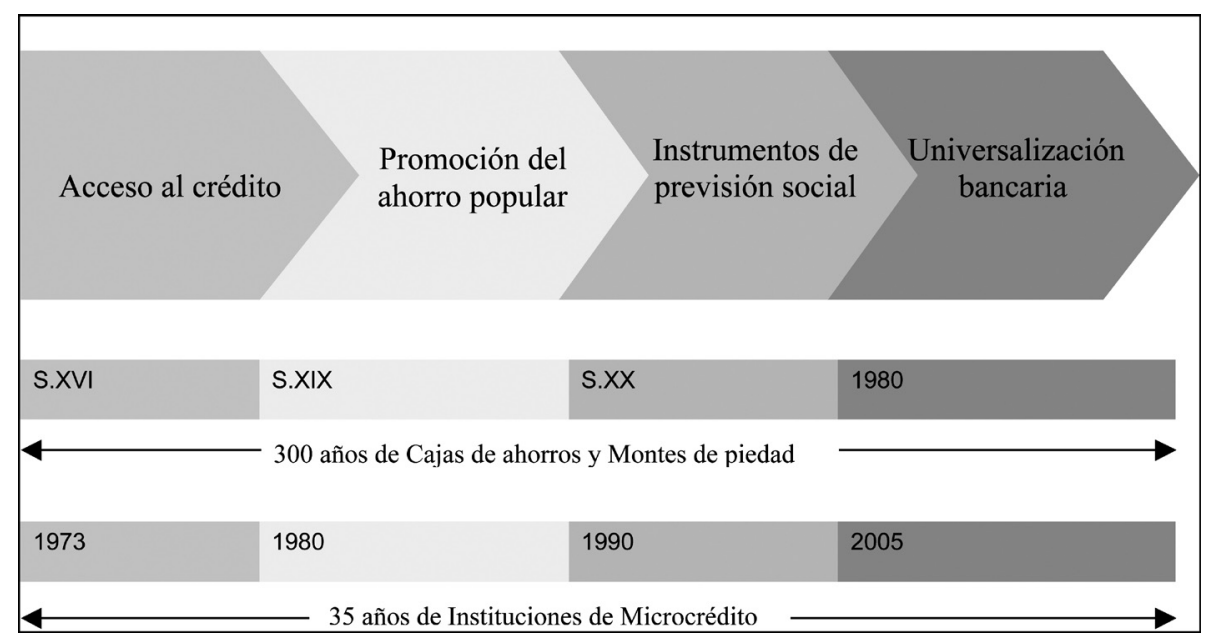

Fuente: Elaboración propia.

\section{I. Etapa Primera:Acceso al crédito}

Las ideas de los padres franciscanos de Perugia, de mediados del siglo XV y el experimento del Profesor Yunus en Daka de 1973 con las artesanas del mimbre tienen una claro punto común: una situación de abuso en el acceso a los recursos económicos necesarios para emprender las actividades productivas de supervivencia de muchas personas pobres, especialmente mujeres. En ambos casos, podemos deducir que la observación de esta situación de abuso les condujo a proponer la solución del crédito como vía de transformación de su realidad concreta.

El acceso al crédito fue una de las primeras herramientas sostenibles que se plantearon como solución a largo plazo y continua siendo hoy uno de los principales frentes de acción de muchas entidades sociales tanto del Primer como del Tercer Mundo. El acceso al crédito, pues, todavía puede ser considerado como un primer nivel de inclusión financiera universal. 


\subsection{Etapa Segunda: Promoción del ahorro popular}

La promoción de la virtud del ahorro, así aparece reflejado en muchos de los primeros escritos de las cajas, atribuyendo al ahorro no únicamente valor económico y previsor, sino valor moral y cultural. Francesc Roca cita en su historia de Caixa Catalunya la definición de ahorro que había escrito el profesor Boix, en 1936: El Ahorro, psicológicamente, es manifestación esmerada del espíritu de previsión; económicamente, por medio de la racionalización individual del consumo y la fuerza acumulativa del patrimonio, es fundamento de estabilización de los factores económicos y base de todo progreso (Roca, 2001).

En cierto modo crédito y ahorro, cuando son aplicados en las economías familiares, son dos mecanismos complementarios, como dos caras de la misma moneda. Tanto el crédito como el ahorro permiten hacer mucho de lo poco, y ampliar lo que es escaso. Mediante el pequeño ahorro se planifican objetivos mayores a medio y largo plazo -desde la compra de los libros de la escuela, hasta la adquisición o mejora de la vivienda-. Mediante el crédito se anticipa una necesidad de hoy que se irá devolviendo poco a poco en el futuro. Ahorro y crédito se complementan y deben mantener un equilibrio.

\subsection{Etapa Tercera: Instrumentos de previsión social}

Esta visión moralizadora del ahorro constituye el primer paso de la concepción de los seguros como instrumentos de previsión y protección social avanzados y apunta hacia uno de los pilares del Estado del Bienestar. La evolución social y económica española no podría ser entendida sin el papel que la seguridad social pública ha jugado, tanto en la prestación de seguros para la vejez y la jubilación, como de seguros de cobertura sanitaria y finalmente, de seguros para las prestaciones del paro. Y como se ha indicado, estas instituciones se basan en las innovaciones introducidas por las cajas de ahorros a principios del siglo XX.

También las instituciones microfinancieras, en su evolución fijan su atención en los seguros para dar servicio a su población objetivo. Así lo describía en 2004 la mayor agrupación internacional de instituciones microfinancieras, INAFI, tras su congreso realizado en Cusco, Perú: La población de escasos recursos es particularmente vulnerable a las desgracias físicas y económicas (fallecimiento, enfermedades, accidentes, desastres naturales, robos, destrucción accidental de su capital de trabajo, etc.). ...Por ello las Instituciones microfinancieras, requieren 
de un conjunto de esfuerzos para salir de los esquemas tradicionales de seguro y poder hacer accesible este producto a los más pobres (INAFI, 2004) ${ }^{8}$.

Del mismo modo, estas instituciones han puesto el punto de mira en el aprovechamiento del potencial de canalización de las remesas de los emigrantes desde los países desarrollados a los países del Sur como nuevo instrumento financiero de previsión social, mediante la transformación de estos fondos, que normalmente se usan en forma de consumo directo, en inversiones productivas para generar negocios e ingresos familiares a largo plazo.

\subsection{Etapa Cuarta: Universalización bancaria}

La historia de las entidades de financiación inclusiva también ha relatado que, a pesar que su nacimiento está muy próximo a las clases más desfavorecidas de la sociedad, en muchos casos acaban ejerciendo de instituciones financieras de carácter universal. Esta transformación tiene diversas explicaciones: el propio crecimiento social y económico de las personas beneficiarias de la actividad primitiva, hace que demanden nuevos servicios financieros de carácter general; el éxito organizativo y financiero hace que estas entidades estén en mejores condiciones de competitividad que otras estructuras financieras de su propio país; se abandona la misión original de servir a los colectivos más pobres para buscar sectores más productivos. En ocasiones, se dan combinaciones entre los diversos argumentos utilizados para alcanzar la universalización de los servicios financieros.

Estos procesos de conversión y transformación son muy sensibles, como ya se ha explicado a lo largo del recorrido histórico y pueden llegar a situaciones finales muy diferentes en función del enfoque utilizado. Desde la situación de las cajas de ahorros británicas o italianas, o algunas microfinancieras que hoy en día son bancos comerciales, cuya transformación supuso la desaparición o eliminación del carácter social que las creó; hasta la situación de muchas entidades de financiación inclusiva, que a pesar de su ampliación de productos, canales, servicios, mercados y clientes, mantienen formal y esencialmente su carácter fiel a sus orígenes.

\footnotetext{
${ }^{8}$ Ver sitio "web" de la INAFI Latinoamerica: www.inafi-la.org/espanol/sem2-05/infgral.htm
} 


\section{Conclusiones}

Las instituciones de financiación inclusiva son entidades con historia, presente y futuro, a tenor de lo expuesto en el presente trabajo. La necesidad social que las generó todavía está muy presente, tanto en las mismas sociedades que las vieron nacer, como, de una forma muy significativa, en los países en vías de desarrollo.

Los dos movimientos analizados parecen haber evolucionado siguiendo un mismo modelo, caracterizado con las cuatro etapas descritas: acceso al crédito; promoción del ahorro popular; incorporación de instrumentos de previsión social; y universalización bancaria. El modelo se justifica plenamente mediante el relato histórico investigado para el caso de los precedentes europeos, españoles y catalanes de los montes de piedad y las cajas de ahorros.

Por el contrario, el modelo sólo parece intuir su validez en el caso de las instituciones microfinancieras, pero será preciso avanzar en nuevas fases de investigación para poder validar plenamente su adecuación plena.

Este modelo no tiene vocación de explicar todos y cada uno de los procesos de transformación de las entidades de financiación inclusiva, sino que debería servir de guía para comprender procesos aparentemente distintos.

Por todo ello, se espera completar el trabajo de aplicación y desarrollo del modelo evolutivo para que se pueda explicar con mayor claridad la evolución que han tenido este tipo de instituciones, y sobre todo, para intuir sus retos de futuro y poder formular las recomendaciones oportunas para que sigan cumpliendo su cometido de integrar a miles de millones de personas pobres de todo el mundo, a través de instrumentos como el crédito, el ahorro, los seguros y las remesas. 


\section{Bibliografía}

Almenar, S. (2003), "Ahorro, laboriosidad y prudencia. Economía Política de las primeras Cajas de ahorros (1704-1835)", Papeles de Economía Española, n 97.

Benaul Berenguer, J. M., Sudrià Triay, C., (2005), "Ahorro e Industria. Burguesía industrial y política inversora de la Caja de Ahorros de Sabadell, 1859-1913", Papeles de Economía Española, n 105/106.

Cals Guell, J. (2005), El éxito de las Cajas de ahorros. Historia reciente, estrategia competitiva y gobierno. Barcelona, Editorial Ariel.

Carbó Valverde, S., López del Paso, R., (2005), "Exclusión financiera: un panorama", Perspectivas del Sistema Financiero, $\mathrm{n}^{\circ} 84$.

Counts, A. (1996), Give Us Credit. New York, Times Books.

DaleY-HARRIS, S. (2002), Pathways Out of Poverty: Innovations in Microfinance for the Poorest Families, Kumarian Press.

De Mesonero Romanos, R., (1851), Memoria del Monte de Piedad y Caja de Ahorros de Madrid. Madrid.

FONT VIDAL, À. (2006), Microcréditos. La rebelión de los bonsáis, Barcelona, Editorial Icaria. Colección Más Madera.

IZARD, M. (1978), El segle XIX. Burgesos i proletaris, Dopesa, p. 35.

Lacalle Calderón, Ma C. (2002), "Los microcréditos: una posibilidad de trabajo y de mejora económica para la familia", Revista de Fomento Social, $\mathrm{n}^{\circ} 225$, eneromarzo, pp. 65-84.

lacalle Calderón, M. C., Marquez Vigil, J., Durán Navarro, J., Rico Garrido, S, Cordero Herrera, L. (2007), El Banco Grammen, Madrid, Foro Nantik Lum de Microfinanzas. Colección Monográficos $n^{\circ} 8$.

López Martín, Ma C., Rodero Franganillo, A. (2007), "Aspectos financieros y legales diferenciales de los microcréditos", Revista de Fomento Social, $n^{\circ} 245$, eneromarzo, pp. 49-68. 
Nowak, M., (2000), La banquière de l'espoir - Celle qui prête aux exclus. Paris, Albin Michel.

- (2005), On ne prête (pas) qu'aux riches. Paris, Éditions Jean-Claude Lattès.

MalkIN, E. (2008), "Microfinance's Success Sets off a Debate in Mexico". The New York Times, 5 de abril de 2008.

Martínez Soto, A. P., (2003), "Las Cajas de ahorros Españolas en el siglo XIX. Los orígenes del sistema, 1839-1875", Papeles de Economía Española, n 97, pp. 174-204.

Martínez Soto, A. P., Cuevas Casaña, J., Hoyo Aparicio, A. (2005), "La historia económica de las Cajas de ahorros Españolas. Una perspectiva institucional y regional del Ahorro, 1830-2004". Papeles de Economía Española, n 105/106.

Montero Carnerero, M. (1983), Bases documentales para la investigación del préstamo y la usura en la sociedad del siglo XIX, Madrid, Confederación Española de Cajas de ahorros, Serie Monografías n 10.

Moragas i Barret, F. (1889), "Las Cajas de ahorros en España". Revista Los Seguros, $\mathrm{n}^{\circ} 4, \mathrm{pp} .78-82$.

- (1898), "Los auxilios de la clase obrera". Revista Los Seguros, n 14 pp. 317-319.

- (1902), "Bases para la redacción de una ley sobre cajas de pensiones para la vejez", Revista Los Seguros, núm 21 pp. 603-614.

Morales Moya, A. (2003), "La historia de España entre 1833 y 1874", Papeles de Economía Española, n 97 pp. 2-13.

Petit Fontseré, J. (1967), Estructura económica de las Cajas de ahorros Catalanas, Barcelona, Ediciones Ariel, pp. 32-33.

Pérez-Bastardas, A. (1999), Francesc Moragas i la Caixa de Pensions (1868-1935), Barcelona, Edicions 62.

Quintás SeOnANe, J. R. (2004), "La gestación del modelo español de cajas", Papeles de Economía Española, n 100. 
Riera Olivé, S., (2005), Les caixes d'estalvis i la protecció social a Catalunya, Col.lecció tesis doctorals CTESC, $n^{\circ} 7$.

RocA, F., (2001), Caixa Catalunya, 75 anys, 1926-2001, Barcelona, Caixa Catalunya.

RocA, J. A. (1968), "Aportación al estudio de los Montes de piedad españoles del siglo XVIII. El Monte de Piedad de Santa Rita de Casia y Caja de Ahorros de Granada", Ahorro, n 51, pp. 19-25.

Tedde DE LoRCA, P. (2003), "La formación de la Economía liberal en España: el contexto de las primeras Cajas de ahorros", Papeles de Economía Española, ${ }^{\circ}$ 97, pp. 15-27

Titos Martínez, M. (2003), "Las Cajas de ahorros en España 1835-1874. Orígenes, organización institucional y evolución financiera". Papeles de Economía Española, n 97. pp. 205-229

Torres Villanueva, E., (2005), "Intervencionismo estatal y cambios en el marco regulador de las Cajas de ahorros durante el primer Franquismo, 1939-1957", Papeles de Economía Española, n 105/106, pp. 16-26.

UnITED NATIONs (2006), Building Inclusive Financial Sectors for Development, Nueva York, United Nations.

Valle Sánchez, V. (2005), "El "Dividendo Social" de las Cajas de ahorros Españolas", Papeles de Economía Española, n 100, Volumen 1.

Voltes Bou, P (1965), Las Cajas de ahorros Barcelonesas. Su pasado, su presente, su porvenir, Barcelona, Fondo Cultural de la Caja de Ahorros Provincial de la Diputación de Barcelona.

- (1965), "Orígenes del Monte de Piedad de Nuestra Señora de la Esperanza", Analecta Sacra Tarraconensia, volumen XXXVII.

Yepes López, J. (1973), Historia Urgente de las Cajas de ahorros y Montes de piedad en España. Madrid, CECA.

Yunus, M. (1997), Vers un monde sans pauvreté, París, Éditions Jean Claude Lattès. 